\title{
The Relationship between Dynamic Balance Ability and Low Limb Isokinetic Muscle Function of Elite Judo Athletes
}

\author{
Lee Jong Baek', Kim Young Kyun ${ }^{2 *}$ \\ ${ }^{1}$ Kookmin University, Republic of Korea \\ ${ }^{2}$ CHA University, Republic of Korea
}

Received: November 29, 2019

Accepted: February 17, 2020

Published online: April 30, 2020

Keywords:

Dynamic Balance

Judo

Performance

Strength
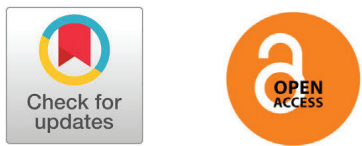

\section{ABSTRACT}

OBJECTIVES The purpose of this study is to examine the relationship between lower extremity isokinetic muscle strength and dynamic balance ability of elite judo athletes and improve the efficient dynamic balance ability of athletes.

METHODS A total of 26 male and female judo national candidates ( 13 males and 13 females) were participated. Isokinetic strength and dynamic balance in three consecutive areas of the lower limbs (knee, hip, waist) were measured. Multiple regression analysis step selection method was used to analyze the correlation between isokinetic strength measurement variables and dynamic balance ability. In addition, the results were analyzed by dividing the difference of fitness variables between male and female athletes and male and female athlete groups.

RESULTS The male athlete group showed higher muscle strength in all areas of isokinetic strength $(p<.01)$. Stability was statistically significantly higher $(p<.05)$. There was interrelationship between the lower extremity isokinetic strength and the dynamic balance of the lower extremities in male and female athletes. The trunk flexion showed the highest correlation with the dynamic balance in the male athletes, and trunk flexion and hip extension in female athletes.

CONCLUSIONS The trunk muscle strength showed the highest correlation with the dynamic balance ability in male and female athletes.

๑ The Asian Society of Kinesiology and the Korean Academy of Kinesiology
서론

균형 능력은 신체의 중심이 지면으로부터 직립 자 세를 유지시키는 과정으로 시각, 전정 기관, 체성감각 기관 사이에서 신속하고 지속적인 피드백에 의하여 신 경근(neuromuscular)간의 협응 작용에 의해 조절된다 [1]. 이러한 신체균형능력은 근골격계 부상의 위험성을 낮추고, 부상 부위의 재손상(re-injury)을 감소시켜 여

*Correspondence: Young Kyun Kim, Department of Sports Medicine, CHA University, Haeryong-ro 120, Pocheon-si, Gyeonggi-do, Republic of Korea; Email: ykkim2020@ cha.ac.kr
러 스포츠 활동에서 운동능력을 최적화 시키는데 크게 기여한다[2-4]. 따라서 낮은 수준의 균형 능력은 근육 과 건, 인대 부상의 위험성을 높이며 [4,5], 특히 고강도 신체활동 중 부상의 확률을 높이는 주요 원인으로 알려 지고 있다[4,6].

이러한 이유에서 대부분의 운동선수들은 다양한 운동 형태의 균형 능력 향상을 위한 훈련이 제안되고 있으며, 가장 일반적인 훈련방법으로는 신경근 훈련 (neuromuscular training)과, 그 다음으로 플라이오메트 릭 운동(plyometric exercise)과 코어안정화운동(core stability exercise)의 통합적인 프로그램으로 제시되고 
있다[7-12]. 하지만 아직까지 이러한 훈련들이 운동수 행능력을 향상시키고 근골격계 손상을 예방하지 못한다 는 연구결과들도 보고되고 있다[13-18].

선수들의 운동수행능력과 균형능력과의 관계에 대 한 연구들은 아직 불분명한 실정이며, 균형 능력 향상 을 위한 대부분의 훈련프로그램이 개인의 특성을 고려 하여 적용하기에는 어려움이 있다[9].

한편, 등속성(isokinetic) 운동은 1960년대 후반부 터 임상 및 스포츠과학 연구에서 관절을 중심으로 근육 의 특성을 파악하기 위하여 다양하게 연구되어 왔으며, 관절부위를 중심으로 한 근력과 근 수축 속도에 대한 연 구와 운동의 효과분석, 운동 상태에 대한 평가와 처방, 재활운동 등의 다양한 스포츠분야에서 이용되고 있다 [20-21]. 이러한 등속성 근력 장비는 스포츠 현장에서 가장 활발하게 활용되고 있지만, 단관절 에 대한 근 기 능분석만 가능하고 관절간의 협응이나, 여러 응용동작 에 대한 평가에는 제한적이다.

현재 등속성 근력을 이용한 초기재활이나 다양한 훈 련프로그램들이 제안되고 있지만 장비의 가격이 고가 인 관계로, 선수들의 근력균형에 대한 평가에 주로 활 용되고 선수들의 훈련에 이용하기에는 어려운 실정이 다[19].

신체 균형에 대한 근육분절들의 개별 특성이 파악된 다면 선수들의 신체균형능력의 구체적인 훈련에 활용하 여 훈련의 효율성을 높일 수 있을 것으로 기대되지만, 아 직까지 선수들의 신체 균형과 근육분절들의 관계에 대 한 연구는 부족한 실정이다. 본 연구에서는 유도 대표팀 선수들의 무릎과 고관절, 몸통 등 연속된 단관절 부위들 의 개별 등속성 근력을 평가하여 직립자세에서의 동적 평형성과의 관계를 분석하고자 한다. 이러한 자료를 토 대로 단관절 근력 특성과 다관절 근력특성과의 운동 사 슬(kinetic chain) 개념의 통합적인 활용 여부를 확인하 고, 신체균형능력에 미치는 분절의 근력 특성을 파악하 여 선수들의 균형능력향상을 위한 훈련프로그램의 기초 자료로 활용하고자 한다. 이를 통해 선수들의 효율적인 균형능력향상으로 운동수행능력 향상과 부상 예방에 기 여할 수 있을 것으로 기대한다.

\section{연구방법}

\section{연구대상}

본 연구의 대상자는 2018년 남녀 유도 국가대표 선
수들로서 남자 $(n=13)$, 여자 $(n=13)$, 총 26명을 대상으로 하였으며 남자 집단과 여자 집단으로 나누어서 하지 등 속성 근력과 동적평형성과의 관계를 분석하였다. 연구 대상자들의 신체적인 특성은 <Table 1 >과 같다.

\begin{tabular}{lll}
\multicolumn{2}{l}{ Table 1. Subject characteristics } \\
\hline Variables & Male $(\mathbf{n}=\mathbf{1 3})$ & Female $(\mathbf{n}=\mathbf{1 3})$ \\
\hline Age (years) & $26.6 \pm 3.43$ & $25.5 \pm 2.11$ \\
Height $(\mathrm{cm})$ & $176.9 \pm 7.24$ & $165.6 \pm 7.42$ \\
Weight $(\mathrm{kg})$ & $93.9 \pm 23.72$ & $67.8 \pm 16.75$ \\
\%Fat $(\%)$ & $16.9 \pm 6.10$ & $19.2 \pm 6.14$ \\
\hline
\end{tabular}

\section{측정 항목 및 방법}

본 연구에서는 유도선수들의 하지 등속성 근력이 동 적평형성에 미치는 영향을 살펴보기 위해 신체 구성과 등속성 근력 3 부위(무릎, 고관절, 몸통), 동적평형성등 의 체력 요인들을 측정하였다. 선수들은 각각 동일한 조 건하에 체력측정을 실시하였으며, 측정 간의 피로로 인 한 다른 측정 항목에 영향을 최소화하기 위하여 중복된 부위에 대한 평가는 30 분 이상의 시간간격을 두고 측 정을 실시하였다.

\section{신체 구성}

신체 구성은 신장계와 체성분분석기(Inbody-720, Inbody, Korea)를 이용하여 신장(height), 체중 (weight), 체지방률(\%fat)을 측정하였다. 신장에는 일 차가 있으므로 측정 시간은 오전 9 11시 사이를 기준 으로 측정하였으며, 기록치는 $\mathrm{cm}$ 단위로 기록하되 소수 점 첫째자리에서 반올림하여 기록했다.

\section{등속성 근력}

하지 관절의 근기능을 측정하기 위한 방법으로 무 릎, 고관절, 몸통 3부위를 등속성근력장비(Cybex 770, Cybex, USA)를 이용하여 측정하였다. 무릎관절의 최대 신전 및 굴곡 운동을 좌우 각각 정해진 운동속도 $(60 \% \mathrm{~s}$ : 5회, $180 \%$ : 5회, $240 \%$ : 26회)로 실시하였으며, 고관절에서 최대 신전 및 굴곡 운동은 좌우 각각 $(30 \%$ : 5회, $180 \%$ : 5 회) 실시하였다. 몸통관절에서의 최대 신전 및 굴곡 각도는 $(30 \%$ s:5회, $120 \%$ : 5 회)로 실시 하였다. 연구대상자간에는 체중이 다르기 때문에 최대 토크 $(\mathrm{Nm})$ 를 측정하여 체중(body weight, $\mathrm{BW}$ )으로 나 눈 상대치 $(\% \mathrm{BW})$ 를 함께 적용하여 제시하였다. 


\section{동적평형성}

동적평형성의 차이를 비교분석하기 위하여 동적평형 성 측정 장비(Balance System SD Biodex, USA)를 활 용하여 전후, 좌우, 전체의 안정성을 측정하였다[22]. 측정은 피험자 모두 맨발인 상황에서 동일하게 실시하 였으며 오른발을 먼저 실시한 이후 왼발을 실시하여 양 발의 동적평형성을 평가하였다. 측정 간에는 5 분간의 휴식을 취한 후 측정을 실시하였으며, 사전에 다른 측 정을 한 피험자는 충분한 휴식 이후 동적평형성 측정을 실시하였다. 측정 프로토콜은 운동선수들의 측정 모델 인 athletes single leg test 에서 level 4모드로 실시 하였으며, 동적평형성의 결과는 세 부위의 측정값을 표 준점수 및 표준편차점수를 구하여 비교하였으며 표준 점수 및 표준편차점수가 낮을수록 안정성이 높은 결과 를 의미한다.

\section{자료처리}

본 연구의 자료처리는 Window SPSS 23.0 버전 통 계 프로그램을 이용하여 평균과 표준편차를 제시하였 다. 유도선수들의 하지 부위별 등속성 최대 근력과 동적 평형성 각 변인간의 관련성을 분석하기 위하여 남녀별 독립표본t검정과 상관관계분석(correlation analysis) 을 실시하였다. 관련이 있는 변인들 중 동적균형성과 상관성이 있는 요소들을 다시 다중회귀분석(multiple regression analysis)을 이용하여 단계선택방식으로 변 인을 투입하여 분석하였다. 상관분석에서 0.9 이상의 상 관관계도가 높은 변인들은 다중공선성 문제를 제거하 기 위해 변인을 제외시켰다. 통계적 유의 수준은 $a=.05$ 로 설정하였다.

\section{결과}

\section{하지 등속성 근력의 남녀 간 차이}

등속성 각근력 굴근과 신근, 고관절 근력의 굴 근과 신근, 몸통근력의 굴근과 신근 등 모든 등속 성 근력에서 남녀 간에 통계적 차이는 〈Table 2〉 과 같다. 모든 등속성 근력 항목에서 통계적으로 높 은 유의한 차이가 있었다 $(\mathrm{p}<.01)$. 남녀 간의 근력 평 균에서 차이를 살펴보면 요근력 신근 $(\mathrm{M}=344.33$, $\mathrm{W}=227.38)$ 에서 평균간 가장 큰 차이가 있었고, 그 다 음 요근력 요근 $(\mathrm{M}=295.92, \mathrm{~W}=176.00)$, 고관절근력 우신근 $(\mathrm{M}=346.77, \mathrm{~W}=231.62)$, 고관절근력 좌신근
$(\mathrm{M}=331.62, \mathrm{~W}=227.38)$ 순서로 근력의 평균 크기의 차이가 있었다.

\begin{tabular}{|c|c|c|c|c|c|c|}
\hline Variables & Group & Mean & SD & $t$ & $p$ & \\
\hline \multirow{2}{*}{$\begin{array}{l}\text { Right } \\
\text { Knee FI }\end{array}$} & M & 125.54 & 19.073 & \multirow{2}{*}{5.949} & \multirow{2}{*}{.000} & \multirow{2}{*}{$* * *$} \\
\hline & W & 78.62 & 21.093 & & & \\
\hline \multirow{2}{*}{$\begin{array}{l}\text { Right } \\
\text { Knee Ex }\end{array}$} & M & 226.46 & 49.978 & \multirow{2}{*}{5.631} & \multirow{2}{*}{.000} & \multirow{2}{*}{$* * *$} \\
\hline & W & 138.85 & 25.491 & & & \\
\hline \multirow{2}{*}{$\begin{array}{l}\text { Left } \\
\text { Knee FI }\end{array}$} & M & 109.69 & 37.933 & \multirow{2}{*}{2.804} & \multirow{2}{*}{.010} & \multirow{2}{*}{ ** } \\
\hline & W & 75.77 & 21.522 & & & \\
\hline \multirow{2}{*}{$\begin{array}{l}\text { Left } \\
\text { Knee Ex }\end{array}$} & M & 202.62 & 76.693 & \multirow{2}{*}{2.824} & \multirow{2}{*}{.009} & \multirow{2}{*}{$* *$} \\
\hline & W & 137.77 & 31.164 & & & \\
\hline \multirow{2}{*}{$\begin{array}{l}\text { Right } \\
\text { Hip FI }\end{array}$} & M & 137.92 & 33.905 & \multirow{2}{*}{5.653} & \multirow{2}{*}{.000} & \multirow{2}{*}{$* * *$} \\
\hline & W & 80.54 & 13.788 & & & \\
\hline \multirow{2}{*}{$\begin{array}{l}\text { Right } \\
\text { Hip Ex }\end{array}$} & M & 346.77 & 72.066 & \multirow{2}{*}{4.288} & \multirow{2}{*}{.000} & \multirow{2}{*}{$* * *$} \\
\hline & W & 231.62 & 64.652 & & & \\
\hline \multirow{2}{*}{$\begin{array}{l}\text { Left } \\
\text { Hip FI }\end{array}$} & M & 133.85 & 33.286 & \multirow{2}{*}{5.173} & \multirow{2}{*}{.000} & \multirow{2}{*}{$* * *$} \\
\hline & W & 78.23 & 19.863 & & & \\
\hline \multirow{2}{*}{$\begin{array}{l}\text { Left } \\
\text { Hip Ex }\end{array}$} & M & 331.62 & 84.339 & \multirow{2}{*}{3.474} & \multirow{2}{*}{.002} & \multirow{2}{*}{$* *$} \\
\hline & W & 227.38 & 67.743 & & & \\
\hline \multirow{2}{*}{$\begin{array}{l}\text { Trunk } \\
\text { Ex }\end{array}$} & M & 344.33 & 81.889 & \multirow{2}{*}{5.035} & \multirow{2}{*}{.000} & $* * *$ \\
\hline & W & 198.20 & 44.899 & & & \\
\hline Trunk & M & 285.92 & 73.358 & 1210 & 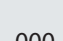 & $* * *$ \\
\hline $\mathrm{FI}$ & W & 176.00 & 35.668 & 4.319 & .000 & \\
\hline
\end{tabular}

${ }^{*} p<.05,{ }^{* *} p<.01,{ }^{* * *} p<.001, \mathrm{M}=\mathrm{Men}, \mathrm{W}=$ Women, $\mathrm{Fl}=$ Flexion, $\mathrm{Ex}=$ Extension

\section{동적평형성의 남녀 간 차이}

동적평형성 의 남녀 간의 차이는 <Table 3 >와 같 다. 우측의 경우 전체균형점수 $(\mathrm{t}=2.486, \mathrm{p}=.020)$ 와 전 후균형점수 $(\mathrm{t}=2.372, \mathrm{p}=.031)$, 좌우균형점수 $(\mathrm{t}=2.353$, $\mathrm{p}=.030)$ 가 통계적으로 유의한 차이 $(\mathrm{p}<.05)$ 가 나타났 다. 좌측은 전체균형점수 $(\mathrm{t}=2.253, \mathrm{p}=.041)$ 만 유의한 차이를 나타냈고 $(\mathrm{p}<.05)$ 다른 요인들은 유의한 차이가 없었다.

\section{하지 등속성 근력과 동적평형성 다중회귀분석}

하지 등속성 근력과 동적평형성의 다중회귀분석 결 과는 <Table 4>와 같다. 좌우 동적평형성은 전체적으 로 몸통 굴근과의 통계적으로 유의한 관계가 나타났다. 각각의 설명력을 살펴보면 표준계수 점수에서 전체균형 능력(overall stability index)과 우측은 $76.6 \%$, 좌측은 
$70.1 \%$ 설명력을 나타냈으며, 전후 균형능력(anterior posterior index)에서는 우측에서 $76.8 \%$, 좌측에 서 $67.3 \%$ 를 나타냈다. 좌우 균형능력(medial lateral index)에서는 우측은 $70.9 \%$, 좌측은 $56.5 \%$ 의 설명력 을 나타냈다.

\begin{tabular}{|c|c|c|c|c|c|c|}
\hline Variables & Group & Mean & SD & $t$ & $p$ & \\
\hline \multirow{2}{*}{$\begin{array}{l}\text { Right } \\
\text { OSI }\end{array}$} & M & 2.515 & 1.2562 & \multirow{2}{*}{2.486} & \multirow{2}{*}{.020} & \multirow{2}{*}{$*$} \\
\hline & W & 1.569 & .5528 & & & \\
\hline \multirow{2}{*}{$\begin{array}{l}\text { Right } \\
\text { API }\end{array}$} & M & 1.869 & 1.0234 & \multirow{2}{*}{2.372} & \multirow{2}{*}{.031} & \multirow{2}{*}{ * } \\
\hline & W & 1.146 & .4013 & & & \\
\hline \multirow{2}{*}{$\begin{array}{l}\text { Right } \\
\text { MLI }\end{array}$} & M & 1.415 & .6517 & \multirow{2}{*}{2.353} & \multirow{2}{*}{.030} & \multirow{2}{*}{$*$} \\
\hline & W & .938 & .3305 & & & \\
\hline \multirow{2}{*}{$\begin{array}{l}\text { Left } \\
\text { OSI }\end{array}$} & M & 2.746 & 1.6353 & \multirow{2}{*}{2.253} & \multirow{2}{*}{.041} & \multirow{2}{*}{$*$} \\
\hline & W & 1.685 & .4598 & & & \\
\hline \multirow{2}{*}{$\begin{array}{l}\text { Left } \\
\text { API }\end{array}$} & $\mathrm{M}$ & 2.131 & 1.5151 & \multirow{2}{*}{2.049} & \multirow{2}{*}{.060} & \\
\hline & W & 1.238 & .4134 & & & \\
\hline \multirow{2}{*}{$\begin{array}{l}\text { Left } \\
\text { MLI }\end{array}$} & M & 1.369 & .5633 & \multirow{2}{*}{2.143} & \multirow{2}{*}{0.44} & \\
\hline & W & .969 & .3683 & & & \\
\hline
\end{tabular}

\section{남자선수집단 하지 등속성 근력과 동적평형성 다중회 귀분석}

남자선수집단의 하지 등속성 근력과 동적평형성의 다중회귀분석 결과는 <Table 5 >과 같다. 좌우 동적평형 성전체적으로 몸통굴근과의 통계적으로 유의한 관계가 나타났다. 각각의 설명력을 살펴보면 표준계수 점수에서 전체균형능력과 우측은 $73.8 \%$, 좌측은 $68.9 \%$ 설명력을 나타냈으며, 전후 균형능력에서는 우측에서 $73.3 \%$, 좌 측에서 $68.2 \%$ 를 나타냈다. 좌우 균형능력에서는 우측은 $78.2 \%$, 좌측은 $73.8 \%$ 의 설명력을 나타냈다.

\section{여자선수집단 하지 등속성 근력과 동적평형성 다중회 귀분석}

여자선수집단의 하지 등속성 근력과 동적평형성의 다중회귀분석 결과는 <Table 6>과 같다. 우측 동적평 형성과 고관절 신전근과 유의한 관계 $(\mathrm{p}<.05)$ 가 나타났 다. 좌측 동적평형성의 경우 몸통신근과 전체균형능력, 전후균형능력과 유의한 관계 $(\mathrm{p}<.05)$ 가 나타났다. 각각의 설명력을 살펴보면 표준계수 점수에서 우측 전체균형능 력과 고관절 신근의 관계는 $81.5 \%$, 좌측 전체균형능력 과 몸통신근은 $75 \%$ 설명력을 나타냈다. 우측 전후 균형 능력에서는 고관절 신근과 몸통 굴신비율이 각각 $91.1 \%$ 의 설명력을 나타냈다. 좌측은 몸통 신근과 $64.7 \%$ 설명 력을 나타냈다. 우측 좌우 균형능력에서는 고관절 신근

Table 4. Lower extremity isokinetic muscle strength and SD balance multiple regression analysis

\begin{tabular}{|c|c|c|c|c|c|c|c|c|}
\hline Variable & Variable & $\begin{array}{c}\text { Unstandardized } \\
\text { coefficients(b) }\end{array}$ & SE & $\beta$ & $t$ & $p$ & Durbin-Watson & $\mathbf{R}^{2}$ \\
\hline \multirow{2}{*}{ ROSI } & (Constant) & -.057 & .399 & & -.142 & .889 & \multirow{2}{*}{2.501} & \multirow{2}{*}{.586} \\
\hline & $\mathrm{TF}(\mathrm{Nm})$ & .009 & .002 & .766 & 5.325 & .000 & & \\
\hline \multirow{2}{*}{ RAPI } & (Constant) & -.088 & .297 & & -.296 & .770 & \multirow{2}{*}{2.471} & \multirow{2}{*}{.590} \\
\hline & $\mathrm{TF}(\mathrm{Nm})$ & .006 & .001 & .768 & 5.369 & .000 & & \\
\hline \multirow{2}{*}{ RMLI } & (Constant) & .050 & .262 & & .190 & .851 & \multirow{2}{*}{2.278} & \multirow{2}{*}{.502} \\
\hline & $\mathrm{TF}(\mathrm{Nm})$ & .001 & .709 & .709 & 4.492 & .005 & & \\
\hline \multirow{2}{*}{ LOSI } & (Constant) & .250 & .437 & & .572 & .574 & \multirow{2}{*}{2.296} & \multirow{2}{*}{.492} \\
\hline & $\mathrm{TF}(\mathrm{Nm})$ & .008 & .002 & .701 & 4.290 & .000 & & \\
\hline \multirow{2}{*}{ LAPI } & (Constant) & .104 & .371 & & .280 & .783 & \multirow{2}{*}{2.046} & \multirow{2}{*}{.453} \\
\hline & $\mathrm{TF}(\mathrm{Nm})$ & .006 & .002 & .673 & 3.964 & .001 & & \\
\hline \multirow{2}{*}{ LMLI } & (Constant) & .328 & .286 & & 1.147 & .266 & \multirow{2}{*}{2.301} & \multirow{2}{*}{.319} \\
\hline & $\mathrm{TF}(\mathrm{Nm})$ & .003 & .001 & .565 & 2.985 & .008 & & \\
\hline
\end{tabular}

${ }^{*} p<.05,{ }^{* *} \mathrm{p}<.01,{ }^{* * *} p<.001, \mathrm{TF}=$ Trunk Flexion

R/LOSI=Right/Left Overall Stability Index, R/LAPI=Right/Left Anterior posterior Index, R/LMLI=Right/Left Medial lateral Index

$\mathrm{SE}=$ Standard Error, $\beta=$ Unstandardized coefficients $((\beta)$ 
Table 5. Lower extremity isokinetic muscle strength and SD balance multiple regression analysis in male athletes

\begin{tabular}{|c|c|c|c|c|c|c|c|c|}
\hline Variable & Variable & $\begin{array}{l}\text { Unstandardized } \\
\text { coefficients(b) }\end{array}$ & SE & $\beta$ & $t$ & $p$ & Durbin-Watson & $\mathbf{R}^{2}$ \\
\hline \multirow{2}{*}{ ROSI } & (Constant) & -.603 & .861 & & -.701 & .499 & \multirow{2}{*}{2.335} & \multirow{2}{*}{.545} \\
\hline & TF (Nm) & .010 & .003 & .738 & 3.463 & .006 & & \\
\hline \multirow{2}{*}{ RAPI } & (Constant) & -.471 & .647 & & -.729 & .483 & \multirow{2}{*}{2.389} & \multirow{2}{*}{.537} \\
\hline & $\mathrm{TF}(\mathrm{Nm})$ & .007 & .002 & .733 & 3.404 & .007 & & \\
\hline \multirow{2}{*}{ RMLI } & (Constant) & -.736 & .540 & & -1.363 & .203 & \multirow{2}{*}{2.528} & \multirow{2}{*}{.611} \\
\hline & $\mathrm{TF}(\mathrm{Nm})$ & .006 & .002 & .782 & 3.962 & .003 & & \\
\hline \multirow{2}{*}{ LOSI } & (Constant) & -.472 & .996 & & -.474 & .647 & \multirow{2}{*}{2.015} & \multirow{2}{*}{.475} \\
\hline & $\mathrm{TF}(\mathrm{Nm})$ & .010 & .003 & 689 & 2.854 & .019 & & \\
\hline \multirow{2}{*}{ LAPI } & (Constant) & -.516 & .815 & & -.634 & .542 & \multirow{2}{*}{2.062} & \multirow{2}{*}{.465} \\
\hline & $\mathrm{TF}(\mathrm{Nm})$ & .008 & .003 & .682 & 2.796 & .021 & & \\
\hline \multirow{2}{*}{ LMLI } & (Constant) & -.603 & .861 & & -.701 & .499 & \multirow{2}{*}{2.335} & \multirow{2}{*}{.545} \\
\hline & $\mathrm{TF}(\mathrm{Nm})$ & .010 & .003 & .738 & 3.463 & .006 & & \\
\hline
\end{tabular}

${ }^{*} p<.05,{ }^{* *} \mathrm{p}<.01,{ }^{* * *} p<.001, \mathrm{TF}=$ Trunk Flexion

R/LOSI=Right/Left Overall Stability Index, R/LAPI=Right/Left Anterior posterior Index, R/LMLI=Right/Left Medial lateral Index $\mathrm{SE}=$ Standard Error, $\beta=$ Unstandardized coefficients $((\beta)$

Table 6. Lower extremity isokinetic muscle strength and SD balance multiple regression analysis in female athletes

\begin{tabular}{|c|c|c|c|c|c|c|c|c|}
\hline Variable & Variable & $\begin{array}{l}\text { Unstandardized } \\
\text { coefficients(b) }\end{array}$ & SE & $\beta$ & $t$ & $p$ & Durbin-Watson & $\mathbf{R}^{2}$ \\
\hline \multirow{2}{*}{ ROSI } & (Constant) & .116 & .380 & & .306 & .768 & \multirow{2}{*}{2.433} & \multirow{2}{*}{.664} \\
\hline & RHE (Nm) & .006 & .002 & .815 & 3.977 & .004 & & \\
\hline \multirow{2}{*}{ RAPI } & (Constant) & .700 & .300 & & 2.332 & .052 & \multirow{2}{*}{1.942} & \multirow{2}{*}{.905} \\
\hline & $\mathrm{RHE}(\mathrm{Nm})$ & .005 & .001 & .911 & 7.809 & .000 & & \\
\hline \multirow{2}{*}{ RMLI } & (Constant) & .293 & .242 & & 1.213 & .260 & \multirow{2}{*}{2.474} & \multirow{2}{*}{.503} \\
\hline & RHE (Nm) & .003 & .001 & .709 & 2.843 & .022 & & \\
\hline \multirow{2}{*}{ LOSI } & (Constant) & -.115 & .590 & & -.196 & .850 & \multirow{2}{*}{1.863} & \multirow{2}{*}{.562} \\
\hline & TF (Nm) & .011 & .003 & .750 & 3.204 & .013 & & \\
\hline \multirow{2}{*}{ LAPI } & (Constant) & -.146 & .605 & & -.242 & .815 & \multirow{2}{*}{1.500} & \multirow{2}{*}{.419} \\
\hline & $\mathrm{TF}(\mathrm{Nm})$ & .008 & .003 & .647 & 2.401 & .043 & & \\
\hline
\end{tabular}

${ }^{*} p<.05,{ }^{* *} p<.01,{ }^{* * *} p<.001, \mathrm{TF}=$ Trunk Flexion, RHE=Right Hip Extensor

R/LOSI=Right/Left Overall Stability Index, R/LAPI=Right/Left Anterior posterior Index, R/LMLI=Right/Left Medial lateral Index

$\mathrm{SE}=$ Standard Error, $\beta=$ Unstandardized coefficients $(\beta)$

이 $70.9 \%$ 의 설명력을 나타냈으며 좌측의 경우 상관관 계가 낮아 회귀관계방정식이 성립하지 못하였다.

\section{논의}

본 연구에서는 현재 남녀 유도 국가대표팀 선수를 대상으로 등속성 근력과 동적평형성의 관련성을 분석 하고자 하였다. 이를 통하여 선수들의 동적평형성 향
상을 위한 분절의 근력 특성을 선수들의 훈련프로그램 에 반영하여 훈련의 효율성 증대시키고 선수들의 운동 수행능력 향상과 부상을 예방을 위한 기초자료로 활용 하고자 하였다.

연구결과, 남녀 선수 간 우측 하지 전체균형과 전후 균형, 좌·우균형 및 좌측하지 전체균형에는 유의한 차 이가 있었다. 이는 와 Ringsberg [23]와 Kligyte [24], McCurdy [25]의 연구들에서도 남녀선수들 간의 근력 
과 균형능력차이가 균형능력에 영향을 미치지 못했다 는 연구결과와 일치하였다. 반면, Blackburn [26]은 6 주간의 근력 또는 고유수용성감각훈련 및 복합훈련 집 단으로 나누어 훈련을 실시한 결과 정적균형능력은 개 선시키지 못하였지만 동적평형성은 증가시킬 수 있다고 하였다. 관절의 기능에서 주동근과 길항근의 적절한 조 화와 균형은 인대의 안정성을 제공하고 관절면에 가해 지는 압력을 균등하게 하는 등 관절의 안정성에 중요한 요인이다. 관절의 안정성은 정적과 동적 기전의 결과물 로, 신체의 정적인 안정성은 뼈, 인대, 관절낭과 같은 수 동적 구조로부터 발생되고, 동적인 안정성은 근수축에 의해 발생된다[27]. 본 연구에서는 정적인 자세에서 움 직이는 동적인 지면에 대한 안정성을 측정한 것으로써 남자선수들은 여자선수들에 비해 근력은 높았지만 관 절의 안정성에 영향을 미치는 주요 변인인 주동근과 길 항근의 비율에서는 차이가 없었고, 무게중심이 낮은 신 체구조적인 특징차이가 여자선수집단의 균형능력이 남 자선수집단보다 더 높게 나타난 이유로 사료된다[28].

하지 등속성 근력과 동적평형성과의 다중회귀분석 결과 오른쪽과 왼쪽의 전체균형과 전후균형, 좌우균형 모두 몸통굴근과 상호관계가 높은 것으로 나타났다. 남 녀별로 구분하여 남자선수들의 등속성 근력과 동적평 형성과의 회귀분석결과에서는 남녀통합 회귀분석결과 와 같이 몸통굴근에서 유의한 관계(right/left overall Index: $\mathrm{p}=.006, \mathrm{p}=.019)$ 를 나타냈다. 오른쪽 전체균형 점수에서는 몸통굴근이 $73.8 \%$ 의 설명력을 나타냈고, 왼쪽 전체균형점수에서는 몸통굴근이 $68.9 \%$ 의 설명력 을 나타냈다. 전후균형점수에서는 몸통굴근이 우측은 $73.3 \%$, 좌측은 $68.2 \%$ 의 설명력을 나타냈다. 좌우균형 에서서는 몸통굴근이 우측은 $78.2 \%$, 좌측은 $73.8 \%$ 의 설명력을 나타냈다. 여자선수들의 등속성 근력과 동적 평형성과의 다중회귀분석결과에서는 우측의 경우 전체 균형점수에서 고관절신근이 $(\mathrm{p}=.004)$ 유의한 관계를 나 타냈고, 균형능력과 $81.5 \%$ 의 설명력을 나타냈다. 우측 전후균형에서는 고관절신근 $(\mathrm{p}=.000)$ 이 관계가 있는 것 으로 나타났고, 고관절 신근이 $91.1 \%$ 의 설명력을 나타 냈다. 왼쪽다리의 균형능력에서는 전체균형과 전후균 형모두 몸통굴근과 관계가 유의하게 $(\mathrm{p}=.013, \mathrm{p}=.043)$ 나타났다. 전체균형에서는 몸통굴근이 $75 \%$ 의 설명력 을 나타냈고, 전후균형에서는 몸통굴근이 $64.7 \%$ 의 설 명력을 나타냈다.
직립 자세 균형능력은 기저면(base of support)과 직 립자세의안정성이 제한(limits of stability)되는 범위에 서 신체중력중심(center of gravity)을 유지하는데 신 체의 능력으로 써 정의될 수 있다. 기저면 안에서 신체 중력중심을 유지했을 때 신체적 안정성이 유지되고, 신 체중력중심이 기저면을 벗어난다면 직립 자세의 안정성 은 감소된다. 자세의 안정성을 유지하기 위해서는 수의 적인 움직임이 일어나기 전 무의식적이고 반사적으로 제어가 일어난다는 운동계의 자동적인 반응 (automatic postural responses)으로 알려져 있다[28, 29]. 이러 한 자동적인 균형유지를 위한 반응들은 크게 발목과 엉 덩이가 주요 균형유지를 담당하며, Horak [17]은 발 목의 체중 이동에 수행능력에 대하여 근전도를 이용하 여 정량화한 연구에서는 전방으로의 체중이동 시 비복 근(gastrocnemius), 대퇴이두근(hamstring), 허리부위 의 옆 근육 순으로 활성화되는 후방근육의 특징적인 패 턴을 보고하였다. 반대로 후방에 대한 근육의 활성화는 전경골근(tibialis anterior), 대퇴사두근(quadriceps), 복부근 등의 순으로 활성화 된다고 하였으며, 내측 체 중이동은 외측근육들을 활성화시키고 외측으로의 체 중이동은 내측의 근육들을 활성화시키며 서로 반대되 는 방향의 근육들이 활성화되는 경향에 대하여 보고하 였다. 특히 Hodges [30, 31]는 복횡근(transversus abdominis)과 같은 심부근육이 자세의 안정화 근육으 로써 기능을 한다고 설명하였으며, 복사근(obliques)과 다열근(multifidus), 복직근(rectus abdominis)등과 같 은 체간근육들이 다양한 방향에 대한 안정성을 유지한 다고 보고하고 있다. 또한 여러 연구들에서도 몸통의 근 력의 신체균형능력과의 높은 상관관계에 대해 보고되고 있다[33-36]. Barati [37]는 일반 건강한 성인을 대상 으로 한 연구에서 몸통의 전후좌우 코어부위의 근지구 력과 정적균형과의 높은 상관관계가 있다고 보고하였고, Yan [38]은 국가대표 프리스타일 스키 남자선수들을 대 상으로 한 연구에서 등속성 몸통근력이 정적균형능력과 상관관계가 있다고 보고하였다. 몸통은 신체의 중심이고 가장 큰 부분으로 크게 두 가지 기능적인 움직임 역할을 수행한다. 첫째, 몸통에서의 근활동은 균형을 유지하면 서 중력에 대응하여 자세를 유지하고, 사지의 움직임을 조율하는 자세적 역할(postural role)이다. 둘째, 일상 생활에서 동적인 역할(dynamic role)로 신체의중심이 동을 원활히 하여 새로운 자세로 쉽게 움직이도록 한다. 
자세적 역할과 동적인 역할은 신체를 사방으로 움직이 기 위한 몸통의 능력이다. 몸통은 중력에 대항하여 단축 성 근활동(concentric muscle activity)움직임과 지지 면으로 향하는 신장성 패턴(eccentric patterns)의 움직 임이 동반되며, 균형(balance)과 팔다리기능(extremity function)에 있어서도 중요한 역할을 담당한다. 몸통이 불안정하면 팔다리는 몸통을 안정시키는데 이용되어 본 래의 기능을 할 수 없기 때문에, 몸통 조절은 모든 기능 적 움직임에 있어서 기본이 된다. 유도선수들의 균형능 력에 미치는 영향에 있어서 몸통부위의 중요성이 등속 성 근력과의 관계에서도 잘 나타난 것으로 사료된다.

한편 남녀공통과 남자선수집단에서 몸통근력 굴근 요추부위에서의 관련성이 높은 이유로는 세계정상급 국 내 남자 유도선수들의 입상성적에 따른 경기력관련 체 력을 비교한 연구에서 우수유도선수집단은 전반적으로 무를 신전근이 유의하게 높은 것으로 보고됐고[35], 신 전근의 활성화 경향은 전반적인 신체의 중심을 앞쪽으 로 기울이게 된다. 현재 한국남자유도선수들은 대부분 업어치기를 주요 공격 기술로 구사하고 있고 이러한 업 어치기 유형의 선수들의 특징으로 힘을 전방으로 미는 동작과 연계되어 있다. 이러한 미는 동작의 특징이 Seo [39]에서 나타난 대퇴신근의 비율과 본 연구에서 몸통 굴근의 상호관계가 높게 나타난 주요요인으로 사료된 다. 여자선수들의 경우 우측 고관절 신근의 관계가 높 게 나타났는데. 국내여자선수들의 기술 패턴을 분석하 여 보면 업어치기기술 활용빈도가 높은 편이지만 남자 선수들에 비해 틀어 잡는 자세가 많으며 이러한 자세에 서 우측 앞발에 체중이 유지되며 고관절신근의 근력과 균형 능력에 차이를 나타내는 주요원인으로 사료된다.

등속성 근력에서는 무릎과 고관절, 몸통 등 모든 등 속성 근력에서 유의한 차이가 있었지만 동적평형성에서 는 남녀 간의 유의한 차이가 나타나지 않았다. 등속성 근 력과 동적균형간의 관계에서는 등속성 근력과 동적평형 성 간에 높은 상관관계를 나타냈고 전체집단, 남자선수 집단, 여자선수집단으로 분류하여 각각을 분석한 결과 에서도 전체적으로 하지 등속성 근력과 동적평형성 간 에 높은 상관관계가 나타났다. 이를 다시 다중회귀분석 결과에서는 전체 집단과 남자선수집단에서는 몸통굴근 이 공통적으로 유의한 상호관계를 나타냈고, 여자선수 집단에서는 좌측의 경우 전체와 남자선수집단과 동일 하게 몸통굴근의 관계가 중요한 것으로 나타났지만 우
측의 경우 고관절 신근의 영향이 큰 것으로 나타났다.

저자는 선행연구 및 가설의 관점에서 결과를 논의하 고 해석 할 수 있어야 한다. 연구 결과와 그 의미는 가능 한 가장 광범위한 맥락에서 논의 되어야한다. 향후 연 구 방향에 대해서 강조 할 수 있으며, 연구의 제한 점에 대해서 논의한다.

\section{결론}

본 연구 결과를 통해 남자선수집단에서는 몸통굴근 즉 코어부위가, 여자선수집단에서는 운동 및 신체적 특 성으로 인하여 고관절 신근에서 동적평형성과 상호관 계가 높은 것으로 나타났다. 본 연구 결과 향후 몸통근 력의 훈련으로 인한 향상이 균형 능력에 긍정적인 영향 을 미치는지에 대한 추가 연구와 성별 및 기간, 훈련 내 용, 체력수준별로 구분한 추가적인 연구가 필요할 것으 로 사료된다.

\section{Conflicts of Interest}

The authors declare no conflict of interest.

\section{References}

1. Winter DA. Human balance and posture control during standing and walking. Gait Posture. 1995; 3(4):193-214.

2. Emery CA. Risk factors for injury in child and adolescent sport: a systematic review of the literature. Clin J Sport Med. 2003; 13(4): 256-268.

3. Hrysomallis C. Relationship between balance ability, training and sports injury risk. Am J Sports Med. 2007; 37(6):547-556.

4. McGuine TA, Greene JJ. Best T et al. Balance as a predictor of ankle injuries in high school basketball players. Clin J Sport Med. 2000; 10(4):239-244.

5. Emery CA, Meeuwisse WH. The effectiveness of a neuromuscular prevention strategy to reduce injuries in youth soccer: a cluster-randomised controlled trial. Br J Sports Med. 2010; 44(8):555-562.

6. Burke-Doe, A, Hudson, A, Werth, H, et al. Knowledge of osteoporosis risk factors and prevalence of risk factors for osteoporosis, falls and fracture in functionally 
independent older adults. J Geriatr Phys Ther. 2008; 31(1):11-17.

7. Hewett TE, Lindenfeld TN, Riccobene JV, et al. The effect of neuromuscular training on the incidence of knee injury in female athletes. Am J Sports Med. 1999; 27(6):699706.

8. Holm I, Fosdahl MA, Friis A, et al. Effect of neuromuscular training on proprioception, balance, muscle strength, and lower limb function in female team handball players. Clin J Sport Med. 2004; 14(2):88-94.

9. Hrysomallis C. Balance ability and athletic performance. Sport Med. 2011; 41(3):221-232.

10. Myer GD, Ford KR, Brent JL, et al. The effects of plyometric vs. dynamic stabilization and balance training on power, balance, and landing force in female athletes. J Strength Cond Res. 2006; 20(2):345.

11. Paterno MV, Myer GD, Ford KR, et al. Neuromuscular training improves single-limb stability in young female athletes. J Orthop Sports Phys Ther. 2004; 34(6):305316.

12. Willardson JM. Core stability training: applications to sports conditioning programs. J Strength Cond Res. 2007; 21(3):979-985.

13. Asadi A, de Villarreal ES, Arazi H. The effects of plyometric type neuromuscular training on postural control performance of male team basketball players. J Strength Cond Res. 2015; 29(7):1870-1875.

14. Karadenizli, ZI. The Effects of plyometric education trainings on balance and some psychomotor characteristics of school handball team. Univers. 2016; 4(10):2292-2299.

15. Karadenizli ZI. The effects of plyometric training on balance, anaerobic power and physical fitness parameters in handball. Anthropol. 2016; 24(3):751761.

16. Lust KR, Sandrey MA, Bulger SM, et al. The effects of 6-week training programs on throwing accuracy, proprioception, and core endurance in baseball. J Sport Rehabil. 2009; 18(3):407-426.

17. Sato K, Mokha M. Does core strength training influence running kinetics, lower-extremity stability, and 5000-
M performance in runners? J Strength Cond Res.2009; 23(1):133-140.

18. Kümmel J, Kramer A, Giboin LS, et al. Specificity of balance training in healthy individuals: a systematic review and meta-analysis. AM J Sport Med. 2016; 46(9):1261-1271.

19. Park HC, Yoon SJ. The effects of plyometric training and isokinetic training of lower limbs on isokinetic muscle strength and jump performance ability. J Sport and Leisure. 2013; 51(2):599-611.

20. Park JS, Lee HY. The effect of peak torque, power and muscle endurance in ankles by 12 weeks isokinetic training. Exercise Sci. 1998; 7(1):81-92.

21. Rothstein JM, Lamb RL, Mayhew TP. Clinical uses of isokinetic measurements: critical issues. Phys Ther.1987; 67(12):1840-1844.

22. Arnold BL, Schmitz RJ. Examination of balance measures produced by the Biodex stability system. J Athl. 1998; 33(4):323.

23. Ringsberg K. Gerdhem P, Johansson J, et al. Is there a relationship between balance, gait performance and muscular strength in 75-year-old women? Age Ageing. 1999; 28(3):289-293.

24. Kligyte I, Lundy-Ekman L, Medeiros JM. Relationship between lower extremity muscle strength and dynamic balance in people post-stroke. Medicina. 2003; 39(2):122-8.

25. McCurdy K, Langford G. The relationship between maximum unilateral squat strength and balance in young adult men and women. J Sports Sci. 2006; 5(2):282.

26. Blackburn T, Guskiewicz KM, Petschauer MA et al. Balance and joint stability: the relative contributions of proprioception and muscular strength. J Sport Rehabil. 2000; 9(4):315-328.

27. Baratta R, Solomonow M, Zhou BH, et al. Muscular coactivation: the role of the antagonist musculature in maintaining knee stability. Am J Sports Med.1998; 16(2):113-122.

28. Lee AJ, Lin WH. The influence of gender and somatotype on single-leg upright standing postural stability in 
children. J Appl Biomech. 2007; 23(3):173-179.

29. Cordo PJ, Nashner LM. Properties of postural adjustments associated with rapid arm movements. J Neurophysiol.1982; 47(2):287-302.

30. Horak FB, Nashner LM. Central programming of postural movements: adaptation to altered support-surface configurations. J Neurophysiol.1986; 55(6):1369-1381.

31. Hodges PW, Richardson CA. Contraction of the abdominal muscles associated with movement of the lower limb. Phys Ther. 1997; 77(2):132-142.

32. Hodges PW, Richardson CA. Feedforward contraction of transversus abdominis is not influenced by the direction of arm movement. Exp Brain Res. 1997; 114(2):362-370.

33. Di Monaco M, Trucco M, Di Monaco R, et al. The relationship between initial trunk control or postural balance and inpatient rehabilitation outcome after stroke: a prospective comparative study. Clin Rehabil. 2010; 24(6):543-554.

34. Granacher U, Gollhofer A, Hortobágyi T, et al. The importance of trunk muscle strength for balance, functional performance, and fall prevention in seniors: a systematic review. Am J Sports Med. 2013; 43(7):627641.

35. Jijimol G, Fayaz RK, Vijesh PV. Correlation of trunk impairment with balance in patients with chronic stroke. NRE. 2013; 32(2):323-325.

36. Verheyden, G, Vereeck L, Truijen S, et al. Trunk performance after stroke and the relationship with balance, gait and functional ability. Clin Rehabil. 2006; 20(5):451-458.

37. Barati A, Safarcherati A, Aghayari A, et al. Evaluation of relationship between trunk muscle endurance and static balance in male students. Asian J Sports Med. 2013; 4(4):289.

38. Yan H, Wang Y. Relationship between static balance ability and trunk muscle strength characteristics of national elite men's freestyle skiing aerials athletes. J Shenyang Sport Univers. 2009;5.

39. Seo TB, Kim TW, Song HS, et al. Comparative analysis of world class national male judo players' athletic performance related physical fitness factors. Exercise Sci. 2014; 23(2):171-179. 